\title{
Position Paper - Key Elements of Remote Offshore Survey Operations
}

\author{
B.M.J. POSSEL, The Netherlands \\ Fugro Survey B.V. \\ H. Swiegers, The Netherlands \\ Fugro Survey B.V.
}

Topics: (D) Smart data management, (E) Easy customer access to data and products, (G) Costeffective solutions

\section{INTRODUCTION}

The advent of data communication between offshore systems and onshore facilities marks a major change that has occurred in the offshore (survey) industry. Up to the previous decade, many floating assets, like rigs, vessels and barges, did not have access to a continuous and global form of data communication. The lack of this capability requires offshore survey staff to perform all necessary tasks unsupported. Furthermore, the collected survey data can only be checked when it is returned to the office. In certain cases the absence of interaction with onshore facilities can contribute to inefficient work processes and errors, this can cause additional (post)processing, operational delays and lead to decreased revenues on projects.

With current technology and (remote control) software a highly reliable and secure data connection can be established to offshore systems. This interaction between offshore survey systems and onshore facilities allows for a number of survey related services to be performed remotely:

- Monitor operations (for example: Quality Control by clients, consultation with survey staff)

- Control operations (starting/stopping measurements, entering waypoints)

- File transfer and data dissemination

- Provide remote support (changing settings, perform calibrations, solving IT-issues)

- Remote meetings (get consensus and real-time feedback from multiple parties).

There are numerous advantages of these services that can be identified: improved project execution, better vessel management and risk mitigation. Support from experienced onshore personnel is available, this can be used to detect and resolve potential issues before they escalate and cause operational delays. Furthermore a reduction in the amount of personnel onsite can be foreseen, which will cut transportation and accommodation costs and limit Health, Safety and Environment (HSE) risks. Disadvantages and risks that can be discerned are: investment costs, reliability issues, unauthorized intrusion into the system and the technology not being accepted.

Major oil companies like Shell, BP and service companies like Schlumberger, have established Real Time Operation Support Centers, allowing remote management of (drilling) operations from anywhere on the world $[1,2,3]$. These centers for remote monitoring and control are mostly used for intercompany purposes; experts provide support and the system can be used for educational purposes. The concept of remote offshore survey operations differs somewhat to that of the above mentioned Operation Support Centers, because it adds (paid) customer services. On the technical side there are also differences, mainly in the network setup. A number of offshore survey companies do already offer remote offshore survey services as a commercial product, like iSURVEY [4] and Fugro Survey B.V. [5].

To perform remote offshore survey operations a number of different fundamental elements are needed; satellite data communication, IT infrastructure, software and technology acceptance. A description of each of these key elements will be given together with the Fugro Survey B.V. implementation and solution. 


\section{RELIABLE INTERNET CONNECTION}

Developments in satellite data communication in the last decade have made data connections, like the Internet, a common concept offshore. There are various satellite Internet systems available on the market, each with specific characteristics that make some systems more usable for certain tasks than others. Required characteristics for data connections used for remote offshore survey operations are: globally operational, high reliability, acceptable latency and cost effective operation.

Many of the global Internet systems utilize Geostationary Earth Orbit (GEO) satellites. The distance between the earth and the geostationary satellite introduces a delay in the signal known as latency; for a two-way connection using GEO satellites this is in the order of $500 \mathrm{~ms}-1000 \mathrm{~ms}$ [6]. Especially for interactive applications, such as remote control of offshore systems, these delays can cause working with the systems to become time-consuming and tedious. Other global Internet systems use lower orbiting satellites which have lower latencies, however there are a number of drawbacks; dozens of satellites are required to provide coverage of the entire planet, a complex and costly ground segment is needed and often the data speed is lower if compared to GEO satellites.

Besides latency also the frequency of signals used for communication plays an important role in satellite communication. C-band and L-band systems have a high resiliency to signal attenuation caused by moisture and precipitation. However these systems have a lower bandwidth compared to higher frequency/higher bandwidth systems (like Ku-band and Ka-band), which can have significant interference due to absorption and scattering by moisture. For a reliable and redundant data connection a combination of satellite communications systems with different frequencies ranges would be the preferred solution.

For projects where survey networks are mobilized on client vessels there is often no independent/dedicated Internet connection available. This means that it is necessary to utilize a client supplied Internet connection. If this is not available or not possible then a solution is to mobilize a designated, portable satellite Internet system.

\section{IT INFRASTRUCTURE}

Offshore survey equipment is specifically designed, configured and interlinked with each other to create a network comparable to small-scale SCADA networks (Supervisory Control And Data Acquisition). Because the nature of many survey projects is ad-hoc and very varied, the total mobilization time of these networks ranges from a few days to several years. Connecting such a survey network over a client network to the Internet requires a flexible, but very basic, network setup. This is because the network architecture and IT-policies vary per client; sometimes lacking access to DNS-servers or prompting the use of proxy-servers. Another limitation is that the connection speed is often very low (even only a few kbps), this is because the Internet connection is shared with all the other users onboard. Access to the survey network by unauthorized individuals should be blocked by taking various precautionary measures [7], for example using very constrained firewalls at both ends of the connection.

Taking these IT-requirements into account, an overview of the current Fugro solution to remote offshore survey operations is presented in Figure 1. The system was developed based on market analysis, expected developments and field trials. The sensors connected to the survey network collect specific data and from there it is sent it over the Internet to a dedicated onshore server. This server is hosted on the Fugro Group Gateway, a server cluster which is scalable, redundant, backed-up and directly connected to the Amsterdam Internet Exchange (AMS-IX). The server also hosts a client website which gives an overview of the status of the ongoing project, effectively a Common Operational Picture (COP). The website can be custom configurable for each client, to track selected vessels on a map, show screenshots of specific offshore computer displays, but also other features like uploading (survey) data or reports. 


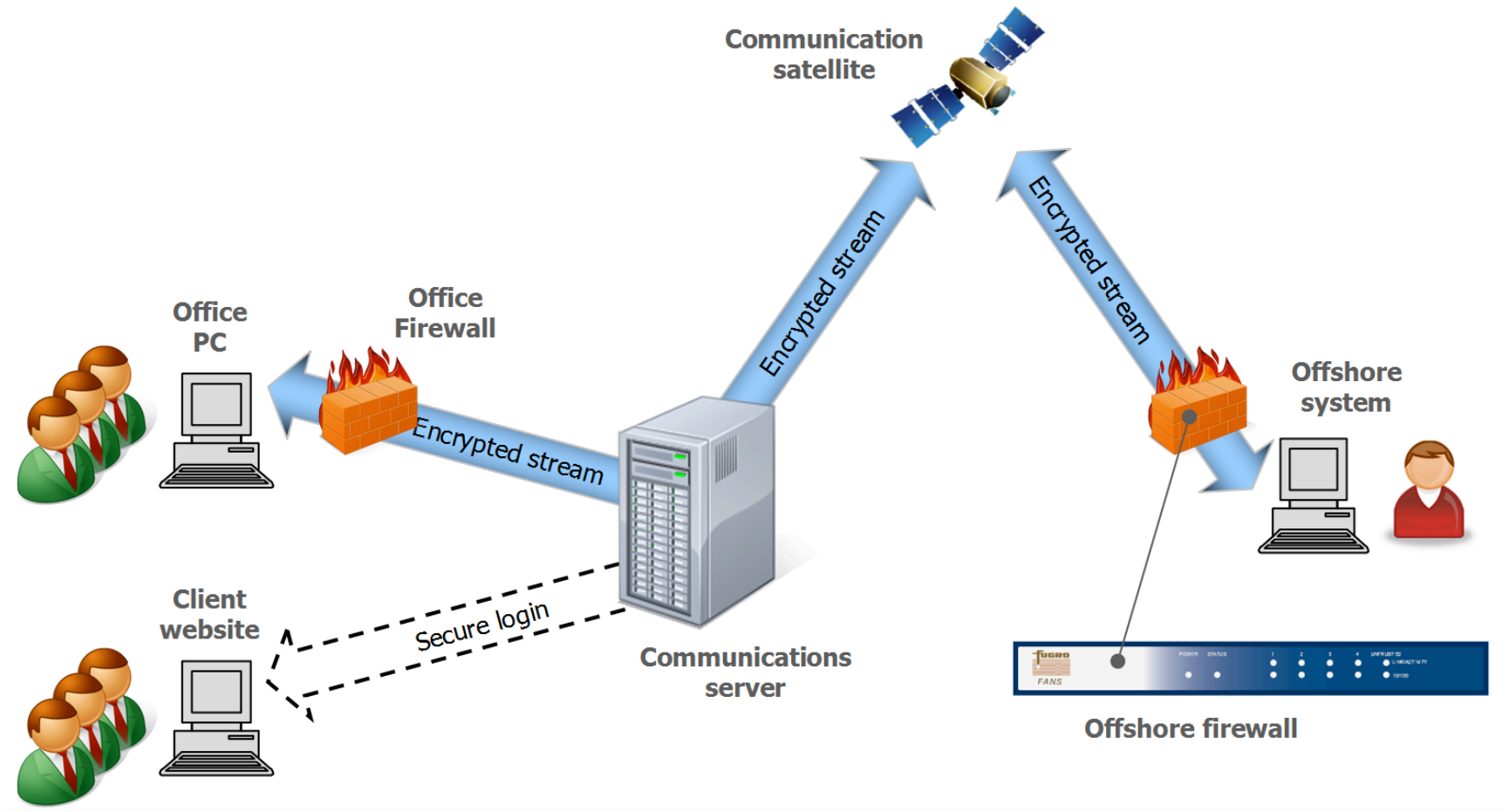

Figure 1: Schematic overview of the current Fugro Remote Services IT infrastructure.

\section{SOFTWARE}

The software needed for remote offshore survey operations has multiple requirements. First of all: to remotely take over control of offshore survey systems/computers, preferably having control of all features. Various processes are required to control drop-outs, low bandwidth and high latency situations. Besides that, a feature that could be incorporated in the software is to remotely switch equipment on and off.

The second objective for remote offshore survey software is to automatically gather specific data. Software installed on the computers onboard should automatically collect measurements of various parameters from the survey network, for example: location, speed, heading, time and vessel name. The collection of other vessel-status information, for example snapshots of the overview screen of the ongoing operations could also be supported.

A third objective is to supply an encrypted connection so data can be securely sent to onshore servers. If data passes through IP-based networks, including the Internet, this raises a number of security issues which can ultimately threaten the integrity of the survey network and security of data. Preventative measures have to be taken to ensure the survey network is not compromised and the collected data are not intercepted.

The software used for Fugro Remote Services supplies access to offshore survey computers using commercially available remote access software, and is protected by double password authentication. In addition, data is automatically collected from the survey network and sent over a HTTPS connection (128-bit AES encrypted) to the server where it is directly updated in the database. Website access is provided to customers using a separate log-in name and unique access code. 


\section{TECHNOLOGY ACCEPTANCE}

In the offshore industry a minimum of risk and a high reliability is of utmost importance, this results in a conservative culture and a tendency to use proven/established technology. Subsequently it takes time and effort to introduce new technology, like the concept of remote offshore (survey) operations. However this new technology will only be successful if the user accepts and uses the technology. A model that theoretically described this effect is the Technology Acceptance Model (TAM) [8]; it presents a number of variables that influence the decision on how and when users will use new technology. The main variables described are:

- Perceived usefulness

- Perceived ease-of-use

To make remote offshore survey operations a more accepted technology, the main focus should thus be on communicating the advantages and possibilities of the system; this can be done by demonstrations, marketing and training. The focus of developments should be to increase the functionality of the system and at the same time to improve usability.

\section{FUTURE DEVELOPMENTS}

In the upcoming years various high speed and low latency global satellite communication systems will be launched, for example Global Xpress and O3B $[9,10]$. This will allow more bandwidth intensive services like live streaming video. Low latency communication systems will improve the quality and speed of remote controlling offshore systems. In addition to that an increase in satellite communication systems will introduce more competition that might force prices down for systems and data-plans, making these systems more affordable and feasible.

Specifically for Fugro Remote Services a number of future developments can be anticipated; the first is a continuously operational Remote Control Centre, which can assist with offshore operations and supply support. Another development is the visualization of related data sources on the customer website to give additional relevant information; this can be weather forecasting, AIS data (Automatic Identification System) or GIS layers on field layout. Also (live) data could be placed in a geo-spatial database and presented with 3D visualization techniques.

\section{CONCLUSION}

Satellite data communication has made interaction between offshore survey systems and onshore facilities possible, which allows a number of survey services to be performed remotely. These can be used as a tool to improve vessel management, control costs and mitigate risks. This paper presents a number of key elements for remote offshore survey operations; satellite data communication, IT infrastructure, software and technology acceptance.

To connect offshore systems to the Internet there are various satellite Internet systems available, each with specific characteristics. Connecting a survey network to the Internet requires a flexible and secure IT-infrastructure, especially when making use of a client network. This needs to be combined with software for remote control of offshore survey systems, automatic data collection and an encrypted connection. To make sure the technology is accepted and used, the advantages and possibilities of remote offshore survey operations should be communicated, together with further development of functionality and the improvement of usability.

\section{REFERENCES}

1) "Shell's Real Time Operation Center solves problems worldwide," Offshore (September 2007): 78. 
2) M. Wahlen et al., "Improving Team Capability and Efficiency by Moving Traditional Rig-Site Services Onshore," BP magazine, issue 4, 2011, accessed May 28, 2012,

http://www.onepetro.org/mslib/servlet/onepetropreview?id=00078336.

3) "Remote Operations, Schlumberger", accessed June 23, 2012,

http://www.slb.com/services/drilling/engineering_modeling/remote_operations.aspx.

4) "iCONTROL by iSURVEY", accessed June 1, 2012, http://www.isurvey-group.com/icontrol.aspx.

5) "Fugro Remote Services Client Website", accessed May 13, 2012, www.fugroremoteservices.com.

6) Mario Marchese, "Performance analysis of the TCP behavior in a geo satellite environment," Computer Communications, Volume 24, Issue 9 (2001): 877-888, http://dx.doi.org/10.1016/S01403664(00)00361-3.

7) Martin Gilje Jaatun, et al, "Secure Safety: Secure Remote Access to Critical Safety Systems in Offshore Installations" in Autonomic and Trusted Computing (Berlin/Heidelberg: Springer, 2008), 121133, http://dx.doi.org/10.1007/978-3-540-69295-9_12.

8) Fred D. Davis, "Perceived usefulness, perceived ease of use, and user acceptance of information technology," MIS Quarterly, Volume 13, Number 3 (1989): 319-340.

9) "Inmarsat Global Xpress", accessed July 2, 2012, http://www.inmarsatgx.com.

10) "O3B Networks", accessed July 3, 2012, http://www.o3bnetworks.com.

\section{BIOGRAPHIES}

Boudewijn POSSEL obtained his MSc. degree in Geomatics at Delft University of Technology in 2009. He is currently working at Fugro Survey B.V. as a Project Surveyor Remote Services, focusing on further development and implementation of remote offshore survey operations.

Hannes SWIEGERS joined Fugro Survey B.V. in 2005, and has been a Construction Support Project Manager since 2007, particular for West African Oil \& Gas projects. Since November 2011 he is the business-line manager for Positioning \& Remote Services.

\section{CONTACT DETAILS}

Boudewijn Possel

Fugro Survey B.V.

Veurse Achterweg 12

P.O. Box 128

2260 AC Leidschendam

The Netherlands

Tel.: +31 70-311 1429

Fax.: +31 70-311 1838

Email: b.possel@fugro.com

Web site: http://www.fugro-africa.com/

LinkedIn account: http://www.linkedin.com/pub/boudewijn-possel/9/a7a/707 